\title{
Cloning and Characterization of Immunological Properties of Haemophilus influenzae Enolase
}

\author{
Yesenia Osorio-Aguilar $\mathbb{D}^{1}{ }^{1}$ Maria Cristina Gonzalez-Vazquez $\mathbb{D},^{1}$ \\ Patricia Lozano-Zarain $\mathbb{D}^{1},{ }^{1}$ Ygnacio Martinez-Laguna, ${ }^{1}$ Alejandro Carabarin-Lima $\mathbb{D}^{1},{ }^{1,2}$ \\ and Rosa del Carmen Rocha-Gracia $\mathbb{D D}^{1}$ \\ ${ }^{1}$ Benemerita Universidad Autonoma de Puebla, Instituto de Ciencias, Centro de Investigaciones en Ciencias Microbiologicas, \\ Posgrado en Microbiologia, Puebla, Puebla, Mexico \\ ${ }^{2}$ Benemerita Universidad Autonoma de Puebla, Instituto de Ciencias, Licenciatura en Biotecnologia, Mexico \\ Correspondence should be addressed to Rosa del Carmen Rocha-Gracia; rochagra@yahoo.com
}

Received 29 December 2020; Revised 19 May 2021; Accepted 4 June 2021; Published 17 June 2021

Academic Editor: Enrique Ortega

Copyright (C) 2021 Yesenia Osorio-Aguilar et al. This is an open access article distributed under the Creative Commons Attribution License, which permits unrestricted use, distribution, and reproduction in any medium, provided the original work is properly cited.

\begin{abstract}
Haemophilus influenzae is a common organism of the human upper respiratory tract; this bacterium is responsible of a wide spectrum for respiratory infections and can generate invasive diseases such as meningitis and septicemia. These infections are associated with $H$. influenzae encapsulated serotype b. However, the incidence of invasive disease caused by nontypeable $H$. influenzae (NTHi) has increased in the post- $H$. influenzae serotype b (Hib) vaccine era. Currently, an effective vaccine against NTHi is not available; due to this, it is important to find an antigen capable to confer protection against NTHi infection. In this study, 10 linear B cell epitopes and 13 CTL epitopes and a putative plasminogen-binding motif $\left({ }_{252}\right.$ FYNKENGMY $\left._{260}\right)$ and the presence of enolase on the surface of different strains of $H$. influenzae were identified in the enolase sequence of $H$. influenzae. Both in silico and experimental results showed that recombinant enolase from $H$. influenzae is immunogenic that could induce a humoral immune response; this was observed mediating the generation of specific polyclonal antibodies anti-rNTHiENO that recognize typeable and nontypeable $H$. influenzae strains. The immunogenic properties and the superficial localization of enolase in $H$. influenzae, important characteristics to be considered as a new candidate for the development of a vaccine, were demonstrated.
\end{abstract}

\section{Introduction}

Haemophilus influenzae is a microorganism that commonly colonizes the upper respiratory tract of both children and adults $[1,2]$. This pathogen causes several types of diseases ranging from respiratory tract infections to severe invasive disease, such as meningitis, sepsis, bacteremia, pneumonia, and epiglottitis [3]. Initially, $H$. influenzae strains were classified in capsulated strains (6 capsular serotypes from type Hia through type Hif) and noncapsulated strains named as nontypeable (NTHi) because these are nonreactive with any typing antisera [4]. For a long time, NTHi was the most frequently isolated bacterial pathogens in noninvasive diseases as otitis media and sinusitis in children $[1,5,6]$. How- ever, there have been reported cases of invasive disease caused by NTHi, and moreover, these bacteria have an important role in exacerbation of chronic obstructive pulmonary disease (COPD) in adults; due to this, NTHi is considered as an emerging pathogen $[7,8]$. Currently, a vaccine that confers protection against diseases caused by NTHi is not available. A big problem to develop a vaccine is the diversity of NTHi clinical isolates [9], so the challenge is to find a common antigen to all NTHi strains to begin with the development of a vaccine.

Enolase or 2-phospho-D-glycerate hydrolase (EC 4.2.1.11) is a metalloenzyme that catalyzes the dehydration of 2-phosphoglycerate (2-PG) to phosphoenolpyruvate (PEP) in the glycolytic way, requires ion magnesium $\left(\mathrm{Mg}^{2+}\right)$ for their 
correct function, and is conserved in all eukaryotic and prokaryotic cells $[10,11]$. However, this enzyme is considered as moonlighting protein with activity as a virulence factor associated with the surface of pathogens [12] and importantly used as potential immunogen against several bacteria such as Streptococcus iniae [13], Staphylococcus aureus [14], and Vibrio parahaemolyticus [15], showing specificity and capacity to confer protection to experimental infected model.

Although several enolases have been studied with potential as immunogens, the role of enolase in NTHi and their immunogenicity is understood. In this study, we analyzed the immunogenic properties of NTHi enolase and determined the potential to develop an efficient vaccine.

\section{Material and Methods}

2.1. Bacterial Strains and Growing Conditions. Four strains (two typeable and two nontypeable) of $H$. influenzae are described as follows: HibBUAPNAN (type b strain, isolated from cerebrospinal fluid from a case of pediatric meningitis), NTHiBUAP96 (strain nontypeable isolated from the middle ear of a case of pediatric otitis media), HiNTBUAPPAU (strain nontypeable isolated from the middle ear of a case of adult otitis media), and HibATCC33930 (strain ATCC of $H$. influenzae type $\mathrm{b}$ isolated from cerebrospinal fluid) [16] were cultured in brain-heart infusion (BHI) agar medium (Bioxon de Mexico) supplemented with 5\% Fildes (peptic digest of sheep blood that supplies the $\mathrm{X}$ (haemin) and $\mathrm{V}$ (nicotinamide adenine dinucleotide, NAD), factors necessary for the adequate growth of $H$. influenzae). The strains were incubated at $37^{\circ} \mathrm{C}, 24 \mathrm{~h}$, in a humid atmosphere containing $5 \% \mathrm{CO}_{2}$. The E. coli DH5 $\alpha$ strain [genetic characteristics: FФ80lacZ $\Delta \mathrm{M} 15 \Delta$ (lacZYA-argF) U169 recA1 endA1 hsdR17 $\left(\mathrm{r}_{\mathrm{k}}^{-}, \mathrm{m}_{\mathrm{k}}{ }^{+}\right)$phoA supE44 thi-1 gyrA96 relA1 $\lambda$-, and BL21 (DE3) pLysS: $\mathrm{F}^{-}$, omp T hsdSB $\left(\mathrm{r}_{\mathrm{B}}{ }^{-} \mathrm{m}_{\mathrm{B}}{ }^{-}\right)$gal dcm (DE3) pLysS $\left.\left(\mathrm{Cam}^{\mathrm{R}}\right)\right]$; both from Invitrogen ${ }^{\mathrm{TM}}$ were grown in LuriaBertani plates or in Luria-Bertani broth (Bioxon de Mexico) and incubated at $37^{\circ} \mathrm{C}$ for $24 \mathrm{~h}$ under aerobic conditions. Where appropriate, media were supplemented with chloramphenicol at $34 \mathrm{mg} \mathrm{mL}^{-1}$ and/or with ampicillin at $100 \mathrm{mg} \mathrm{mL}^{-1}$.

2.2. Hieno Gene Amplification and Sequencing. The DNA fragment that codes for Haemophilus influenzae enolase (Hieno) was amplified from purified genomic DNA of four $H$. influenzae strains (HibBUAPNAN, NTHiBUAP96, HiNTBUAPPAU, and HibATCC33930) by polymerase chain reaction (PCR) using a forward primer $\left(5^{\prime}\right.$-CTCGAGATGGCAAAAATCGTTAAAG TGATTG- $\left.3^{\prime}\right)$ and a reverse primer $\left(5^{\prime}-G G T A C C C T T G A C C T\right.$ TTAACCGCTTTTAAG-3') that introduced both XhoI and KpnI restriction sites (italicized), respectively.

The PCR reaction carried out in a volume of $25 \mu \mathrm{L}$ contained $1 \mu \mathrm{g}$ of template, $2 \mathrm{mM}$ of forward and reverse primers, $2 \mathrm{mM} \mathrm{MgCl}, 0.2 \mathrm{mM}$ of each dNTP, $1 \mathrm{X}$ PCR buffer, and $2.5 \mathrm{U}$ of Taq DNA polymerase (NEB, MA, USA). The amplification conditions were $95^{\circ} \mathrm{C}$ for $1 \mathrm{~min}, 58^{\circ} \mathrm{C}$ for 1 min, and $72^{\circ} \mathrm{C}$ for $2 \mathrm{~min}$ for 30 cycles, and $72^{\circ} \mathrm{C}$ for $10 \mathrm{~min}$. Subsequently, the PCR products of one typeable and one nontypeable strain were cloned in $\mathrm{pCR}^{\circledR} 2.1-\mathrm{TOPO}$ vector (LacZ $\alpha$ operon, multiple cloning site, $\mathrm{T} 7$ promoter, $\mathrm{fl}$ origin, kanamycin and ampicillin resistance, and pUC origin, Invitrogen $^{\mathrm{TM}}$ by Life Technologies, Carlsbad, CA, USA). The resulting plasmids (TOPO::HibBUAPNANeno and TOPO::NTHiBUAP96eno) were transformed in Escherichia coli $\mathrm{DH} 5 \alpha$ cells, and the recombinant positive clones were picked up and later sequenced. The sequence corresponding to NTHiBUAP96eno (NTHiENO) was submitted to GenBank (access number: MF405339.1).

2.3. Bioinformatics Analysis. From the database of National Center for Biotechnology Information (NCBI), the sequences of enolase of different microorganisms which presented greater homology with Hieno by Basic Local Alignment Sequence Tool (http://www.ncbi.nlm.nih.gov/BLAST), as well as the sequences where enolase has been used as a vaccine, were obtained. Amino acid sequences were aligned using ClustalW (http://www.ebi.ac.uk/Tools/msa/clustalw2/), and neighbor-joining analysis was performed employing the MEGA X package [17].

The enolase human sequence was used as an outgroup. Gaps were treated as pairwise deletions; amino acid distances were calculated using the Poisson model, and branch support was estimated using bootstrap analysis (1000 bootstraps). Furthermore, the NTHiENO sequence was analyzed to calculate its molecular weight; isoelectric point (pI) and stability index were assessed using ExPASy ProtParam server (http:// ca.expasy.org/tools/protparam/html), posttranslation modification sites by MotifScan (http://myhits.isb-sib.ch/cgi-bin/ motif_scan), functional domain and key sites by InterProScan (http://www.ebi.ac.uk/InterProScan/), transmembranal region and topology structure by TMpred (http://www.ch .embnet.org/software/TMPRED_form.html), and secondary structure and disulfide bond by PredictProtein (http://www .predictprotein.org/), and linear B cell epitopes were predicted using BepiPred 2.0 Server (http://www.cbs.dtu.dk/ services/BepiPred/) and CTL epitopes by NetCTL 1.2 Server (http://www.cbs.dtu.dk/services/NetCTL/). Proteasomal cleavage sites in CTL epitopes were predicted by NetChop 3.1 server (http://www.cbs.dtu.dk/services/NetChop/); on the other hand, the prediction of antigenicity of NTHiENO was predicted using VaxiJen v.2.0 server (http://www.ddg-pharmfac.net/ vaxijen/scripts/VaxiJen_scripts/VaxiJen3.pl) and the allergenicity was made by AllergenFP v.1.0 (https://ddg-pharmfac .net/AllergenFP/feedback.py).

2.4. Subcloning, Expression, and Purification of HiENO. The Hieno DNA sequence was digested from TOPO::NTHiBUAP96eno and TOPO:: HibBUAPNANeno plasmids by double enzyme digestion with XhoI and KpnI and subcloned into the expression vector pRSET-A (overexpression vector, $\mathrm{Amp}^{\mathrm{r}}$, and 6x His, Invitrogen ${ }^{\mathrm{TM}}$ by Life Technologies, Carlsbad, CA, USA), obtaining the plasmids pRSET-A::HiNTBUAP96eno and pRSET-A::HibBUAPNANeno; the correct subcloning was confirmed by restriction enzyme analysis and sequencing (results not shown). Since the enolase sequences of the typeable and nontypeable strains present a high degree of homology, approximately of $99 \%$, we decided to obtain only the recombinant enolase of NTHiBUAP96 strain (rNTHiENO) as described below. 
E. coli BL21(DE3) pLysS cell containing the plasmid pRSET-A::HiNTBUAP96eno was grown to mid-logarithmic phase at $37^{\circ} \mathrm{C}$, in Luria-Bertani (LB) medium supplemented with ampicillin $\left(100 \mathrm{mg} \mathrm{mL}^{-1}\right)$ and chloramphenicol (34 $\left.\mathrm{mg} \mathrm{mL}^{-1}\right)$; subsequently, isopropyl $\beta$-D-1-thiogalactopyranoside (IPTG) was added at a final concentration of $1 \mathrm{mM}$ to induce overexpression of the recombinant protein (rNTHiENO); the culture was kept 3 hours in constant shaking at $37^{\circ} \mathrm{C}$. After induced expression, the bacterial cells were collected by centrifugation at $8000 \times g$ for $5 \mathrm{~min}$ at $4^{\circ} \mathrm{C}$. The final pellet was resuspended in $20 \mathrm{mM}$ Tris- $\mathrm{HCl}(\mathrm{pH} 8.0)$, $500 \mathrm{mM} \mathrm{NaCl}$, and $5 \mathrm{mM}$ imidazole and disrupted by sonication, followed by centrifugation at $8000 \times g$ for $10 \mathrm{~min}$ at $4^{\circ} \mathrm{C}$; the supernatant was obtained, and the recombinant protein (rNTHiENO) was purified through Ni-NTA-agarose affinity chromatography (Qiagen, Hilden, Germany) according to the manufacturer's instructions. The rNTHiENO was eluted with elution buffer $20 \mathrm{mM}$ Tris- $\mathrm{HCl}(\mathrm{pH}=8.0), 500 \mathrm{mM}$ $\mathrm{NaCl}$, and $1 \mathrm{M}$ imidazole. Finally, purified rNTHiENO was resolved on $12 \%$ sodium dodecyl sulfate-polyacrylamide gel electrophoresis (SDS-PAGE) to analyze its expression. Aliquots of the purified protein were stored at $-80^{\circ} \mathrm{C}$, and the protein concentration was determined using the Bradford protein assay.

\subsection{Identification of rNTHiENO by Western Blot Analysis.} Purified recombinant rNTHiENO $(10 \mu \mathrm{g})$ was resolved on a $12 \%$ SDS-PAGE and electrotransferred onto nitrocellulose membrane at $15 \mathrm{~V}$ for $40 \mathrm{~min}$. The membranes were blocked with a blocking buffer (5\% skimmed milk $(w / v$ in phosphatebuffered saline (PBS))) for $1 \mathrm{~h}$ at $37^{\circ} \mathrm{C}$ under gentle agitation, followed by three washes with PBS containing $0.05 \%$ Tween-20 (PBST), and then were incubated overnight at $4^{\circ} \mathrm{C}$ with antihistidine monoclonal antibody (Thermo Fisher Scientific) at 1:5000 dilution in 2\% skimmed milk-PBS.

After the washing procedure, the membranes were subsequently incubated with anti-mouse IgG alkaline phosphatase-conjugated secondary antibody $\left(\mathrm{Novex}^{\circledR}\right.$ by Life Technologies) diluted at $1: 5000$ for $1 \mathrm{~h}$ at $37^{\circ} \mathrm{C}$, and the signal was revealed with nitro blue tetrazolium (NBT) chloride and 5-bromo-4-chloro- $3^{\prime}$-indolyphosphate p-toluidine salt (BCIP) (Thermo Fisher Scientific).

2.6. Generation of rNTHiENO Polyclonal Antibodies. For the immunization scheme, eight New Zealand rabbits were randomly assigned to the control or immunized groups of four animals each. The rabbits were bled to collect preimmune sera; later, they were immunized with $100 \mu \mathrm{g}$ of rNTHiENO with complete Freund's adjuvant (CFA) (Sigma) by intramuscular puncture, followed by three boosters with the same concentration of recombinant protein emulsified with incomplete Freund's adjuvant (IFA) (Sigma) in a period of fifteen days each. The control group received PBS/adjuvant in the same schedule as the immunized rabbits; at the end of the immunization scheme, the rabbits were bled to obtain the hyperimmune sera. The rabbits were housed in a controlled environment and managed according to the National Institutes of Health Guide to the Care and Use of Experimental Animals and followed the guidelines of the Norma Official
Mexicana Guide for the Care and Use of Laboratory Animals (NOM-062-ZOO-1999) and with the approval of the Claude Bernal Animal Care and Use Committee of the Benemerita Universidad Autonoma de Puebla.

2.7. Generation of H. influenzae Polyclonal Antibodies. Polyclonal antiserums against the NTHiBUAP96 and HibBUAPNAN were obtained as follows: a culture of either bacteria NTHi or Hib was recovered in sterile PBS until $10^{9} \mathrm{CFU} / \mathrm{mL}$ was obtained and an aliquot with $0.3 \mathrm{~mL}$ was subcutaneously injected into two New Zealand rabbits (2.5-3.0 kg) emulsified with an equal volume of complete Freund's adjuvant. The animals received four booster injections (on days 14, 22, 30, and 38 after initial priming immunization) in the presence of incomplete Freund's adjuvant. Antibody titers were examined by western blot at $0,2,3$, and 4 weeks after the last immunization, and the animals were sedated and killed by cardiac exsanguination at the end of the fourth week and the serum collected was stored at $-20^{\circ} \mathrm{C}$ until use.

2.8. Enolase Identification by Indirect Immunofluorescence (IFI). For microscopic examinations, bacteria (NTHiBUAP96, NTHiBUAPPAU, HibBUAPNAN, and HibATCC33930) were grown overnight on cultures in BHI supplemented with Fildes at $37^{\circ} \mathrm{C}$. Later, a drop containing two to three colonies was resuspended in $10 \mu \mathrm{L}$ of PBS and was pipette onto a glass slide, dried and fixed with $4 \%$ paraformaldehyde (PFA) in phosphate-buffered saline (PBS) $\mathrm{pH} 7.4$ for $30 \mathrm{~min}$ at room temperature. Slides were washed two times in PBS. After that, samples were incubated all night at $4^{\circ} \mathrm{C}$ with anti-rNTHiENO polyclonal antiserum (dilution 1:50 in $0.1 \%$ bovine serum albumin in PBS) and another $60 \mathrm{~min}$ at $37^{\circ} \mathrm{C}$ with anti-rabbit FITC-labeled IgG purchased from Zymax ${ }^{\mathrm{TM}}$ (dilution 1:250 in BSA-PBS). The slides were then washed with PBS, and $8 \mu \mathrm{L}$ of VECTASHIELD Antifade Mounting Medium with DAPI (Vector Laboratories) was added to the sample before topping with a coverslip. All preparations were examined by epifluorescence microscopy using a Motic BA410E microscope with a $60 \mathrm{x}$ or $100 \mathrm{x}$ oil immersion objectives. Ten to twenty fields of each sample were acquired using a Digital WiFi Microscope Camera Moticam X2 (Motic). Images were analyzed and processed using Motic camera software.

2.9. Wild Enolase Identification by Western Blot. Briefly, $H$. influenzae strains (typeable and nontypeable) were harvested from cultures and resuspended in lysis buffer $(10 \mathrm{mM}$ Tris$\mathrm{HCl}, \mathrm{pH}$ 7.5; $5 \mathrm{mM}$ EDTA; $1 \%$ Nonidet P-40; $1 \mathrm{mM}$ phenylmethanesulfonyl fluoride; $10 \mathrm{mg} / \mathrm{mL}$ aprotinin; 50 U/L Trasylol; $10 \mathrm{mg} / \mathrm{mL}$ leupeptin) by repeated freezing and thawing cycles. Lysates were cleared by centrifugation $\left(30 \mathrm{~min}, 4^{\circ} \mathrm{C}\right.$ at $\left.14000 \times \mathrm{g}\right)$, and the supernatants were collected and resolved by $12 \%$ sodium dodecyl sulfatepolyacrylamide gel electrophoresis (SDS-PAGE, $10 \mu \mathrm{g}$ per lane) or purified rNTHiENO (10 $\mu \mathrm{g}$ per lane). Proteins were electrotransferred onto nitrocellulose membranes at $15 \mathrm{~V}$ for $40 \mathrm{~min}$. The membranes were blocked with a blocking buffer (5\% skimmed milk ( $w / v$ in phosphate-buffered saline (PBS))) for $1 \mathrm{~h}$ at $37^{\circ} \mathrm{C}$, washed three times with PBS containing $0.05 \%$ Tween-20 (PBS-T), and then incubated overnight at 
$4^{\circ} \mathrm{C}$ with anti-rNTHiENO polyclonal antibodies $(1: 1000$ dilution in $2 \%$ skimmed milk-PBS). For the titration assay, $10 \mu \mathrm{g}$ per lane of rNTHiENO was migrated and electrotransferred; after that, different dilutions of the anti-rNTHiENO polyclonal antiserum were performed $(1: 1000 ; 1: 10000 ; 1$ : 20000; $1: 50000 ; 1: 40000$ in $2 \%$ skimmed milk-PBS). The negative control consisted of a pool of serum from different healthy rabbits diluted at 1:500 in 2\% skimmed milk-PBS. After washing, the membranes were incubated with secondary antibody conjugated with alkaline phosphatase (Millipore) for $1 \mathrm{~h}$ at $37^{\circ} \mathrm{C}$ and diluted at 1:5000 in $2 \%$ skimmed milk-PBS. The blots were visualized with nitro blue tetrazolium (NBT) chloride and 5-bromo-4-chloro-3'-indolyphosphate p-toluidine salt (BCIP) (Thermo Scientific).

\section{Results}

3.1. Obtaining the DNA Fragment That Codes for Hieno. From purified DNA genomic of several $H$. influenzae strains typeable and nontypeable, the encoding region to enolase of NTHiBUAP96 was ligated to the pRSET-A vector. PCR reaction was performed with the aim to obtain the DNA fragment that codes for Hieno. A band of $1.3 \mathrm{kbp}$ was obtained in all strains assayed HibATCC33930, HiNTBUAPPAU, HibBUAPNAN, and HiNTBUAP96 (Figure 1(a)). After that, the product corresponding to fragment that codes for Hieno of HibBUAPNAN and HiNTBUAP96 was subcloned into pRSET-A plasmid (Figure 1(b)), and the construction result was sequenced to confirm that the PCR product inserted corresponds to fragment that codes for Hieno.

The complete enolase sequences of both HibBUAPNAN and NTHiBUAP96 strains were obtained, which have 99.54\% homology. NTHiBUAPPAU and HibBUAP33930 just obtained the partial sequence. The sequences obtained in this study were compared with the enolase of typeable and nontypeable $H$. influenzae strains that are available in the database of National Center for Biotechnology Information (NCBI); the results showed $>99 \%$ homology. These results indicate that the enolase sequences in all H. influenzae strains have no significant difference (data not shown). The sequence corresponding to NTHiBUAP96eno (NTHiENO) was submitted to GenBank (access number: MF405339.1).

The traduced sequence reports that NTHiENO (HiNTBUAP96) has 437 amino acids with a theoretical molecular weight and $\mathrm{pI}$ of $46.30 \mathrm{kDa}$ and 5.03 , respectively. The half-life was estimated at $30 \mathrm{~h}$, and the protein was classified as stable with a stability index (II) of 28.60 (a value below 40 is considered stable).

The in silico analyses were made with the enolase sequence of both strains, but the results yielded the same data; for this reason, the results are only shown for the enolase of the NTHiBUAP96 strain.

\subsection{Bioinformatics Assays with the NTHiENO Sequence}

3.2.1. Identification of the Catalytic and Metal-Binding Site. With the aim to identify if NTHiENO sequence contains the characteristic motif of enolases, several sequences were downloaded of the DataBank (PubMed) and alignments were done. HiENO sequence shows a strong identity as well as with the heterologous sequence of Vibrio parahaemolitycus (85\%). With other enolase sequences (bacteria, parasites, and eucarya organism), HiENO showed identity percent ranging from $57 \%$ to $24 \%$ (Figure 2). The alignment between this enolase's sequences revealed that NTHiENO presents the motifs of enolase as $\mathrm{Mg}^{2+}$-binding sites, substratebinding sites, the sequence considered as enolase signature, the fingerprint motif, putative plasminogen-binding motif, and exRNA-binding sites (Table 1).

3.2.2. Identification of the Plasminogen-Binding Site. With the aim to localize a putative site for interaction with plasminogen in the NTHiENO sequence, an alignment was realized and a putative plasminogen-binding site $\left({ }_{252}\right.$ FYNKENGMY $\left._{260}\right)$ was identified; this site really is present in several sequences of parasites and bacteria, which is inclusive and had an important percent of homology (55.5\%) with the characterized plasminogen-binding site in S. pneumoniae (Table 1). This result indicates that $H$. influenzae enolase could bind to the human plasminogen through this putative plasminogenbinding motif as has been demonstrated in other models.

3.2.3. Identification of Host-Derived Extracellular RNA(exRNA-) Binding Sites. Recently, it has been demonstrated in $S$. pneumoniae the presence of six exRNA-binding sites in the enolase protein; moreover, these motifs are important for the adhesion to and its internalization into different cells [18]. Therefore, in this study, the putative exRNA-binding sites in NTHiENO sequence were identified. NTHiENO shows five out of six exRNA-binding sites with an identity between 44 and 85\% (Table 1); importantly, they conserved amino acids with positive charge (lysine and arginine) presumptively implicated in the interaction with exRNA. Only one motif was not present in NTHiENO corresponding to ${ }_{432} \mathrm{LKK}_{434}$ motif, located in the C-terminal region of $S$. pneumoniae enolase. Although it is unknown if $H$. influenzae interact with exRNA, there is a possibility that HiENO may interact with the host-derived exRNA, favoring adhesion to the host's cells. However, experimental studies are required to verify this.

3.2.4. Phylogenetic Analysis. The phylogenetic analysis showed that two major clades are grouped, one corresponding to eukaryotic (support value 91\%) and the other one to prokaryotic (support value 63\%) organism. Furthermore, NTHiENO is partaking of the node with $V$. parahaemolyticus (Figure 3).

3.2.5. Predicted Epitopes for $B$ and $T$ Cells. With the NTHiENO amino acids, traduced sequences realized predictions to determine if this protein could be immunogenic. The bioinformatics assays predicted the presence of 10 linear B cell epitopes and 13 CTL epitopes conserved into several HLA supertype alleles (Figure 4). The 13 CTL epitopes were examined for the presence of proteasomal cleavage sites using NetChop 3.1 program. All the epitopes displayed several cleavage sites to be processed by the proteasome; this processing by cytosolic pathway is essential for a peptide to 


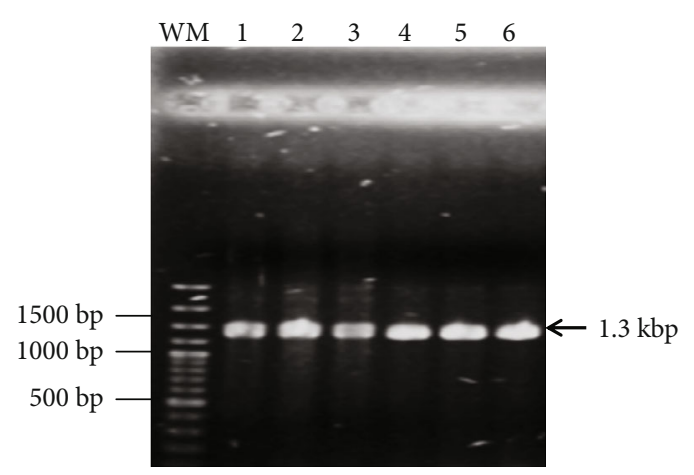

(a)

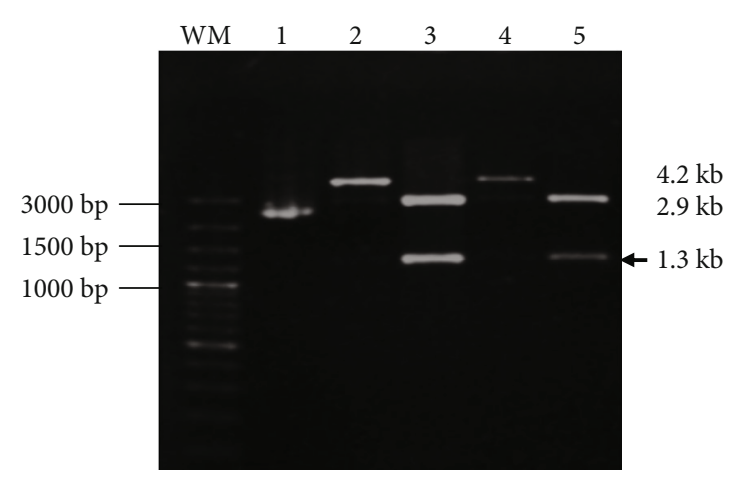

(b)

FIgURE 1: DNA fragment encoding Hieno, amplification, and subcloning. (a) Agarose gel stained with ethidium bromide revealing the 1.3 kbp-sized PCR amplification products (arrow): HibATCC33930 (lane 1), NTHiBUAPPAU (lane 2), HibBUAPNAN (lane 3), amplified obtained using TOPO::HibBUAPNANeno plasmid as a template (lane 4), NTHiBUAP96 (lane 5), and amplified obtained using TOPO::NTHiBUAP96eno plasmid as a template (lane 6). (b) Design and construction of pRSET-A::HiENO plasmid. Lane 1: pRSET-A/XhoI digested $(2.9 \mathrm{kbp})$. Lane 2: pRSET-A::HibBUAPNAN plasmid/XhoI. Lane 3: pRSET-A::HibBUAPNAN plasmid digested with XhoI and KpnI. Lane 4: pRSET-A::NTHiBUAP96 plasmid/Xho. Lane 5: pRSET-A::NTHiBUAP96 plasmid digested with XhoI and KpnI enzymes in a double restriction reaction. The product of $1.3 \mathrm{kbp}$ corresponding to Hieno gene is observed (arrow).

act as CTL epitope. Further, four predicted B cell epitopes have overlapped with CTL epitopes (Table 2).

3.2.6. Prediction of Antigenicity and Allergenicity. The antigenicity prediction results by VaxiJen v.2.0 showed a value of 0.4828 (probable antigen); in turn, AllergenFP v.1.0 classifies it as a nonallergen protein; these in silico results indicate that NTHiENO is antigenic and should not cause an allergic reaction inside of the body.

3.2.7. Predicted a Transmembrane (TM) Domain. With the aim to know if $H$. influenzae enolase could be in surface, a bioinformatics assay was realized. These studies showed that enolase sequences have a predicted transmembranal domain in the region comprised by amino acids $\mathrm{Asn}_{105}-\mathrm{Ala}_{124}$. Through this transmembranal domain, enolase could be anchoring to the cell surface in $H$. influenzae (Supplementary Figure 1).

3.3. Expression and Purification of rNTHiENO. The enolase encoding region of NTHiBUAP96 was ligated to the pRSET-A vector and expressed as a His-tag fusion protein in E. coli BL21 (DE3) pLysS cells. The purified protein had a predicted size of approximately $52 \mathrm{kDa}$, which includes an approximately $6 \mathrm{kDa}$ peptide corresponding to tag fusion (Figure 5(a), lane 5). Then, the purified $\mathrm{H}$. influenzae enolase was recognized as a single band (approximately $52 \mathrm{kDa}$ ) by western blot assays using a monoclonal anti-His antibody (Figure 5(b), lane 2). A slight signal was identified in extract of E. coli Bl21 with the noninduced recombinant plasmid (Figure 5(b), lane 1).

3.4. Polyclonal Antibodies Anti-NTHiENO Are Specifics. In this study, rabbits were immunized with rNTHiENO to produce polyclonal antibodies. At the end of the immunization scheme, polyclonal anti-rNTHiENO antibodies were quantified and a high titer $(1: 40000)$ was observed by western blot assay (Figure 6). After that, the serum of these immunized rabbits was used in western blot assays as a first antibody against $H$. influenzae typeable and nontypeable total protein extracts and purified rNTHiENO; these antibodies were capable to detect a band of $52 \mathrm{kDa}$ (Figure 7, lane 9) demonstrating a strong reactivity and antigenicity of rNTHiENO. Moreover, anti-rNTHiENO polyclonal antibodies specifically recognized an approximately $46 \mathrm{kDa}$ band in all total protein extracts of $H$. influenzae (Figure 7, lanes 1-8), which corresponded to the predicted native size of $H$. influenzae enolase and shows a good specificity.

The antibodies generated against rNTHiENO were also used in immunofluorescence assays against typeable (Hib) and nontypeable $H$. influenzae strains. In nonpermeabilized bacteria, the labeling was found in the membrane of both strains, while intense fluorescence is observed in NTHi and also observed spots of fluorescence on Hib strains. This localization might facilitate its recognition by the host's immune system, suggesting that NTHiENO could have strong antigenic properties (Figure 8).

\section{Discussion}

$H$. influenzae is a bacterium with medical importance because it is the cause of a great variety of local and systemic infections, which mainly affects children under 5 years, adults over 65 years, and immunocompromised individuals [19]. In 1989, the vaccine against $H$. influenzae serotype b was introduced, which has been very successful [20-22]. However, it does not protect against the rest of the serotypes or against nontypeable strains. Recent studies have reported an increase in the incidence of invasive infections caused by non-Hib strains [8]. A study conducted in Bogotá, Colombia, in the period of 2002-2013 was isolated to different strains of $H$. influenzae from invasive diseases. 50.5\% were of patients with meningitis, $23.5 \%$ of pneumonias, $19.5 \%$ of sepsis and bacteremia, $2.0 \%$ of others, and $4.5 \%$ without data, where the predominant serotype was Hib (40.5\%), followed by HiNT (38.0\%), Hia (17.5\%), Hid (2.0\%), Hif (1.5\%), and Hie $(0.5 \%)$ [23]. It is important to mention that continuous 


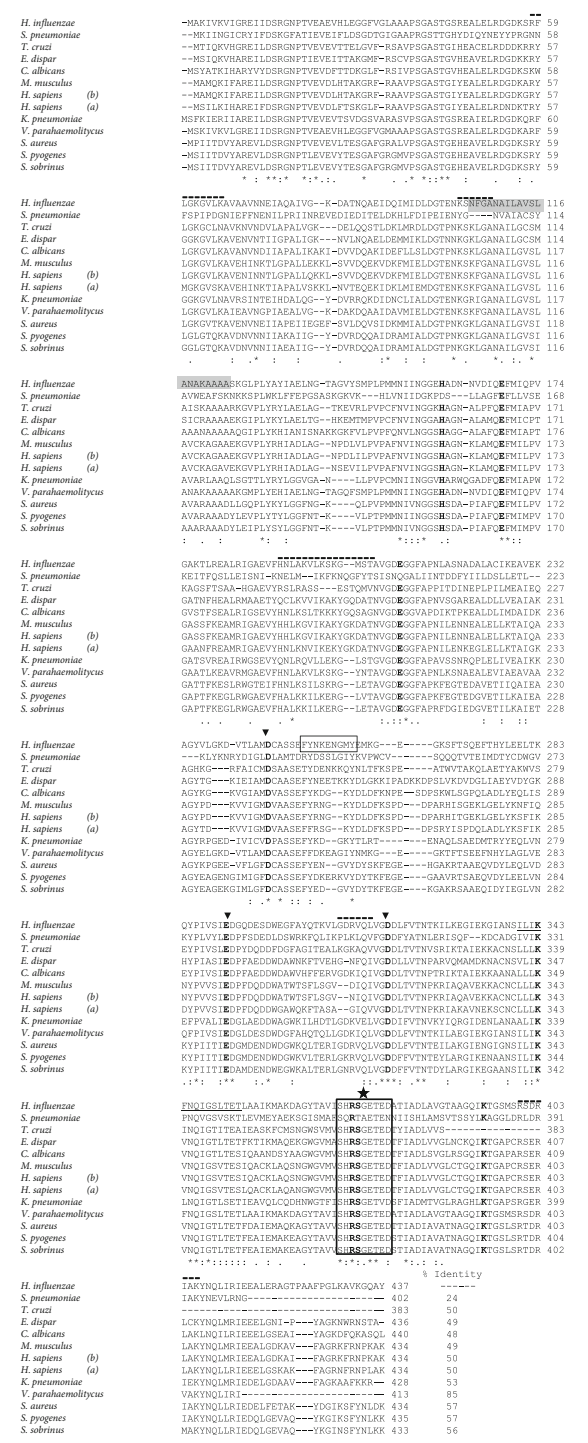

FIGURE 2: Comparative analysis by alignment of the amino acid sequences of several enolases: Haemophilus influenzae NTHiENO (ASO96723.1), Streptococcus pneumoniae (CTN02995.1), Trypanosoma cruzi (AGR66223.1), Entamoeba dispar (EDR27966.1), Candida albicans (AAA71939.1), Mus musculus (CAA40913.1), Homo sapiens $\beta$-enolase (NP_001967.3), Homo sapiens $\alpha$-enolase (NP_001419.1), Klebsiella pneumoniae (SAW34188.1), Vibrio parahaemolyticus (KZW93652.1), Staphylococcus aureus (BBA234 31.1), Streptococcus pyogenes (AKI77548.1), Streptococcus sobrinus (CAD60544.1); parentheses show GenBank accession numbers. The conserved amino acids in all sequences are labeled with asterisks; the conservative and semiconservative substitutions are labeled with two and one points, respectively. The dashed lines shown gaps introduced between the sequences. The residues involved in $\mathrm{Mg}^{2+}$ binding are shown in bold and with arrowhead, those forming the enolase signature are underlined, and the motifs for substrate binding are indicated with letters in bold. The putative plasminogenbinding site is boxed. The transmembranal domain is indicated in shadowed gray. The enolase "fingerprint" motif is boxed and shown with star. RNA-binding motifs are indicated with dashed bold lines over the motive. The percentage of sequence identity between NTHiENO and the enolases from other organisms is indicated at the end of figure. surveillance is essential for all $H$. influenzae infections, since non-b serotypes and nontypeable strains can become the main cause of invasive diseases [24].

The lack of a vaccine that generates protection against all serotypes and nontypeable strains promotes the search for new antigens with immunogenic potential against this bacterium.

On the other hand, due to biotechnological approach, the massive sequencing of the genome of multiple microorganisms and the design of bioinformatics tools have given way to the use of reverse vaccinology, a recent approach and first described by Rappuoli in early 2000 [25, 26]. This method is used to predict antigens through the development of genomics and bioinformatics tools [27].

Enolase is an essential enzyme in the metabolism of glucose in different organisms [28]; however, the presence of this protein has been demonstrated on the cell surface of some microorganisms such as bacteria, parasites, and yeasts, where it is found as a plasminogen receptor, and moreover, it has also been shown to be an antigen capable of generating a specific and protective immune response that leads to the neutralization of an infection [13, 15, 29-33].

Due to the above discussion, in this work, we studied the presence of enolase on surface of $H$. influenzae and if NTHiENO could be immunogenic and even more, and if it could generate cross immunogenicity for the typeable and nontypeable $H$. influenzae strains.

Initially, the cloning, expression, and in silico characterization of the enolase of NTH. influenzae were performed by molecular and immunological techniques. The results demonstrated the rNTHiENO recombinant protein has an approximate weight of $52 \mathrm{kDa}$ fused to His-tag (Figure 5(a), lane 5), and this band was identified by western blot, using anti-His $_{6 \mathrm{X}}$ monoclonal antibodies (Figure 5(b), lane 2). However, to identify the wild enolase in several $H$. influenzae strains (NTHi and Hib) in total protein extracts, a band with an approximate weight of $46.30 \mathrm{kDa}$ was resolved (Figure 7 , lanes 1-8). These results coincide with the enolase weights reported for $V$. parahaemolyticus $(48 \mathrm{kDa})$ [15], S. iniae $(47 \mathrm{kDa})$ [13], C. albicans $(47 \mathrm{kDa})$ [34], T. cruzi $(46.01$ $\mathrm{kDa})$ [35], and A. actinomycetemcomitans (47 kDa) [36].

On the other hand, a multiple alignment of the enolase of different species was performed, in which the expression of enolase in the cell surface has been reported, functioning as a receptor to plasminogen (Figure 2 and Table 1 ).

It is important to highlight that the enolase of the HiNTBUAP96 and HibBUAPNAN strains has a 99.54\% identity; this result indicates that the change between the amino acid sequence of the typable and nontypable strains is not significant. The bacterial enolase with the highest identity with NTHiENO is $V$. parahaemolyticus (85\%), and NTHiENO has the lowest identity with human enolases (50\%). With the rest of the species, it has a $24-57 \%$ identity. Also were identified are the essential residues for its activity, such as the catalytic site and magnesium-binding residues, which determine the necessary conformation for dimerization and enzymatic function as well as the signature of enolase. These motifs coincide with reported by different authors [13, 28, 32, 35].

Plasminogen is a $92 \mathrm{kDa}$ proenzyme; the $\mathrm{N}$-terminal region of plasminogen contains five kringle domains of 80 
TABLE 1: Biochemical characteristics of NTH. influenzae enolase.

\begin{tabular}{|c|c|c|c|}
\hline Feature & H. influenzae & S. pneumoniae & H. sapiens \\
\hline \multirow{4}{*}{$\mathrm{Mg}^{2+}$} & $\mathrm{D}_{244}$ & $\mathrm{D}_{242}$ & $\mathrm{~S}_{40}$ \\
\hline & $E_{291}$ & $E_{291}$ & $\mathrm{D}_{245}$ \\
\hline & & & $\mathrm{E}_{293}$ \\
\hline & $\mathrm{D}_{318}$ & $\mathrm{D}_{318}$ & $\mathrm{D}_{318}$ \\
\hline \multirow{9}{*}{ Catalytic sites } & $\mathrm{H}_{159}$ & $\mathrm{H}_{155}$ & $\mathrm{H}_{158}$ \\
\hline & $\mathrm{E}_{168}$ & $\mathrm{E}_{164}$ & $\mathrm{E}_{167}$ \\
\hline & $E_{209}$ & $\mathrm{E}_{205}$ & $\mathrm{E}_{210}$ \\
\hline & $\mathrm{D}_{318}$ & $\mathrm{E}_{291}$ & $\mathrm{E}_{293}$ \\
\hline & $\mathrm{K}_{343}$ & $\mathrm{D}_{318}$ & $\mathrm{D}_{318}$ \\
\hline & $\mathrm{R}_{372}$ & $\mathrm{~K}_{343}$ & $\mathrm{~K}_{343}$ \\
\hline & $\mathrm{S}_{373}$ & $\mathrm{R}_{372}$ & $\mathrm{R}_{372}$ \\
\hline & $\mathrm{K}_{394}$ & $\mathrm{~S}_{373}$ & $S_{373}$ \\
\hline & & $\mathrm{K}_{394}$ & $\mathrm{~K}_{394}$ \\
\hline \multirow{6}{*}{ RNA binding $(\%)^{\mathrm{a}}$} & ${ }_{58}$ RFLGKGVLK $_{66}(44 \%)$ & ${ }_{58} \mathrm{RYGGLGTQK}_{66}$ & ${ }_{56} \mathrm{RYMGKGVSK}_{64}$ \\
\hline & ${ }_{103} \mathrm{KSNFGA}_{108}(50 \%)$ & ${ }_{103} \mathrm{KGKLGA}_{108}$ & ${ }_{103} \mathrm{KSKFGA}_{108}$ \\
\hline & ${ }_{191}$ HNLAKVLKSKGMSTA $_{205}(60 \%)$ & ${ }_{187}$HALKKILKSRGLETA $_{201}$ & ${ }_{190} \mathrm{HNLKNVIKEKYGKDATN}_{206}$ \\
\hline & ${ }_{310} \operatorname{GDRVQL}_{315}(66.67 \%)$ & ${ }_{310} \mathrm{GKKVQL}_{315}$ & ${ }_{312} \mathrm{GIQV}_{315}$ \\
\hline & ${ }_{400} \operatorname{RSDRIAK}_{406}(85.71 \%)$ & ${ }^{400}$ RTDRIAK $^{406}$ & ${ }^{400}{ }_{\text {RSERLAK }}^{406}$ \\
\hline & & ${ }_{432} \mathrm{LKK}_{434}$ & ${ }_{432} \mathrm{LAK}_{434}$ \\
\hline Enolase signature & ${ }_{340}$ ILIKFNQIGSLTET $_{353}$ & ${ }_{340} \mathrm{ILIKVNQIGTLTET}_{353}$ & ${ }_{340}$ LLLKVNQIGSVTES $_{353}$ \\
\hline Plasminogen binding $(\%)^{\mathrm{b}}$ & ${ }_{252}{ }_{\text {FYNKENGMY }}{ }_{260}(55.5 \%)$ & ${ }_{248} \mathrm{FYDKERKVY}_{256}$ & ${ }_{251}$ FFRSGKY $_{257}$ \\
\hline
\end{tabular}

${ }^{\mathrm{a}}$ Homology percent with respect to exRNA-binding sites in S. pneumoniae [17]. ${ }^{\mathrm{b}}$ Homology percent with respect to plasminogen-binding site in S. pneumoniae [29].

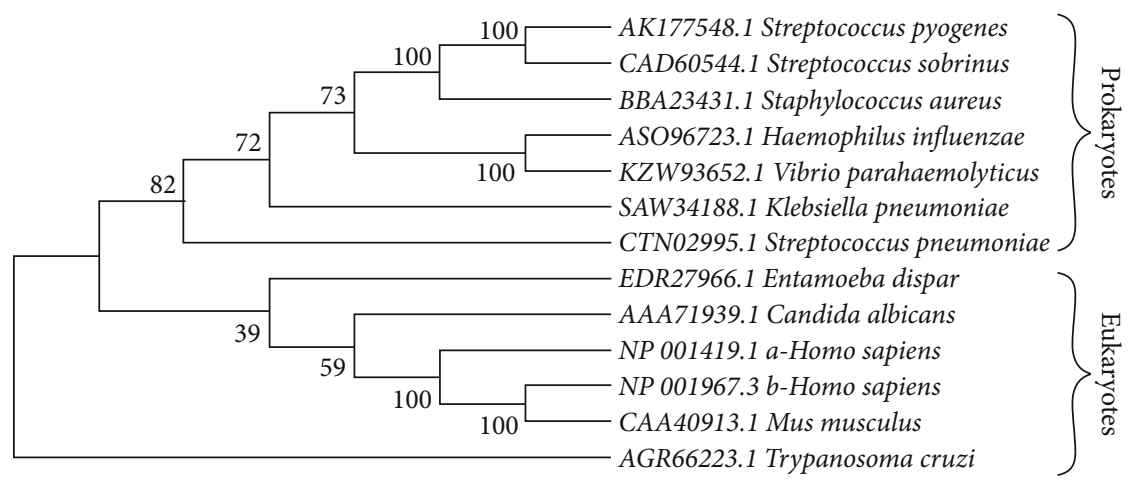

Figure 3: Evolutionary relationships of NTHiENO. The evolutionary history was inferred using the neighbor-joining method [56]. The bootstrap consensus tree inferred from 1000 replicates [57] is taken to represent the evolutionary history of the taxa analyzed [57]. Branches corresponding to partitions reproduced in less than $50 \%$ bootstrap replicates are collapsed. The percentages of replicate trees in which the associated taxa clustered together in the bootstrap test (1000 replicates) are shown next to the branches [57]. The evolutionary distances were computed using the Poisson correction method [58] and are in the units of the number of amino acid substitutions per site. This analysis involved 13 amino acid sequences. All ambiguous positions were removed for each sequence pair (pairwise deletion option). There were a total of 454 positions in the final dataset. Evolutionary analyses were conducted in MEGA X [17].

amino acids, which contain lysine-binding sites [37, 38]; interaction with lysine leads to a conformational change, which makes it more susceptible to cleavage by plasminogen activators (PAs) [39].

An internal motif responsible for plasminogen binding that is exhibiting affinity for kringle domains has been identified in enolase of multiple organisms such as V. parahaemo- lyticus [15], Streptococcus mutans [40], Streptococcus iniae [13], Leishmania mexicana [41], and Trypanosoma cruzi [35]. A predicted plasminogen-binding motif ${ }_{252} \mathrm{FYN}$ KENGMY $_{260}$ ) was identified in the enolase sequence of $H$. influenzae; this motif showed a $55.5 \%$ similarity with the nine amino acid motifs detected in enolase of S. pneumoniae (FYDKERKVY; the crucial residues for plasminogen binding 


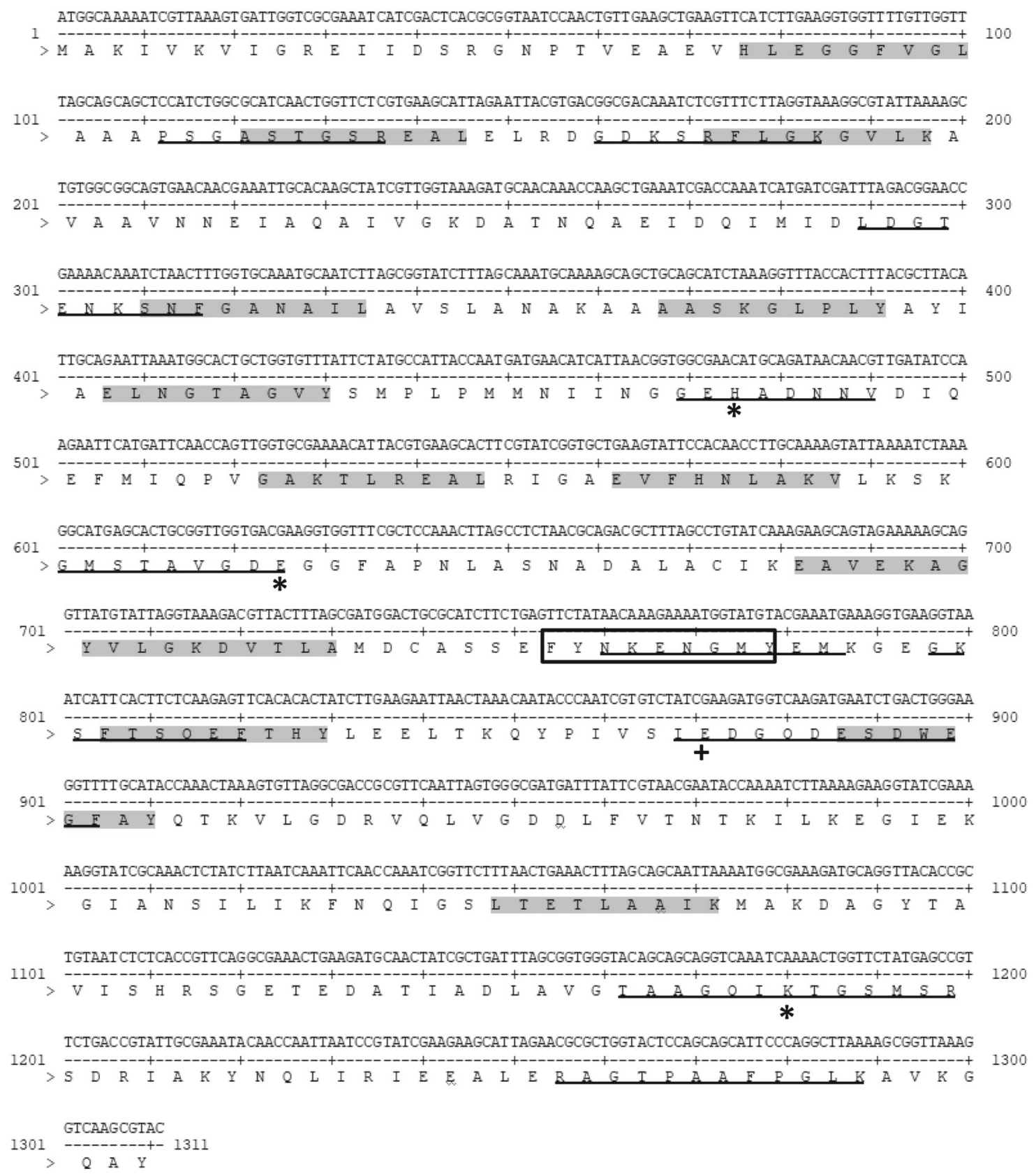

FIgURE 4: Predicted NTHiENO B and T cell epitopes. The coding region of NTHiENO gene and its translated protein sequence are shown; linear B cell epitopes are underlined; CTL epitopes are shadowed in gray. An asterisk indicates the amino acids involved in the catalytic site $\left(\mathrm{H}_{159}, \mathrm{E}_{209}\right.$, and $\left.\mathrm{K}_{394}\right)$ and with a plus sign and the amino acid involved in binding to $\mathrm{Mg}^{2+}$.

are shown in italics). It is reported that point mutations of these amino acids greatly decrease the binding to plasminogen $[30,40]$. Of the three important amino acids, Lys 255 and Glu256 are conserved in enolase sequence of $H$. influen$z a e$. These data allow us to assume that HiENO could interact with human plasminogen through this putative motif identified in its sequence and that Lys 255 and Glu256 could be important residues to mediate this interaction, which has already been well characterized in S. pneumoniae.
On the other hand, the expression of exRNA has been demonstrated in important biological fluids as the blood, semen, saliva, vaginal secretions, and menstrual blood [42]. In $S$. pneumoniae, it has been demonstrated that enolase sequence presents six important binding motifs to exRNA, and moreover, these motifs promote adhesion to endothelial and epithelial cells [18]. In Helicobacter pylori enolase, it was also demonstrated the presence of five motifs conserved that might interact with host-derived exRNA [43]. In this study, 
TABLE 2: Cytotoxic T lymphocyte epitopes for different HLA supertypes predicted in NTH. influenzae enolase.

\begin{tabular}{|c|c|c|c|c|}
\hline Peptide no. & Peptide sequence & HLA super type & Overlapping with B epitope & Proteasomal cleavage sites \\
\hline 1 & HLEGGFVGL & A26, B39, B44 & No & Yes (2 sites) \\
\hline 2 & ASTGSREAL & B7, B39 & Yes & Yes (4 sites) \\
\hline 3 & RFLGKGVLK & A3, B27, B29 & Yes & Yes (4 sites) \\
\hline 4 & SNFGANAIL & $\mathrm{A} 2, \mathrm{~B} 39, \mathrm{~B} 58$ & No & Yes (2 sites) \\
\hline 5 & AASKGLPLY & $\mathrm{A} 1, \mathrm{~A} 3, \mathrm{~A} 26, \mathrm{~B} 7, \mathrm{~B} 58, \mathrm{~B} 62$ & No & Yes (3 sites) \\
\hline 6 & ELNGTAGVY & $\mathrm{A} 1, \mathrm{~A} 26, \mathrm{~B} 44, \mathrm{~B} 62$ & No & Yes (3 sites) \\
\hline 7 & GAKTLREAL & B7, B8, B58 & No & Yes (3 sites) \\
\hline 8 & EVFHNLAKV & A26, B8, B44 & No & Yes (4 sites) \\
\hline 9 & EAVEKAGYV & A26, B7, B39 & No & Yes (3 sites) \\
\hline 10 & YVLGKDUTL & $\mathrm{A} 2, \mathrm{~B} 8, \mathrm{~B} 39, \mathrm{~B} 62$ & No & Yes (5 sites) \\
\hline 11 & FTSQEFTHY & $\mathrm{A} 1, \mathrm{~A} 26, \mathrm{~B} 39, \mathrm{~B} 44, \mathrm{~B} 58, \mathrm{~B} 62$ & Yes & Yes (4 sites) \\
\hline 12 & ESDWEGFAY & $\mathrm{A} 1, \mathrm{~A} 26, \mathrm{~B} 44, \mathrm{~B} 58$ & Yes & Yes (2 sites) \\
\hline 13 & LTETLAAIK & $\mathrm{A} 1, \mathrm{~A} 2, \mathrm{~A} 3, \mathrm{~B} 44$ & No & Yes (4 sites) \\
\hline
\end{tabular}

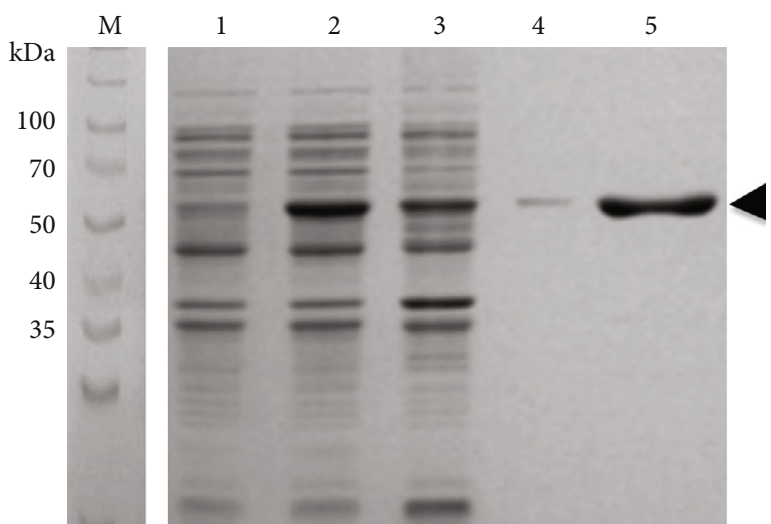

(a)

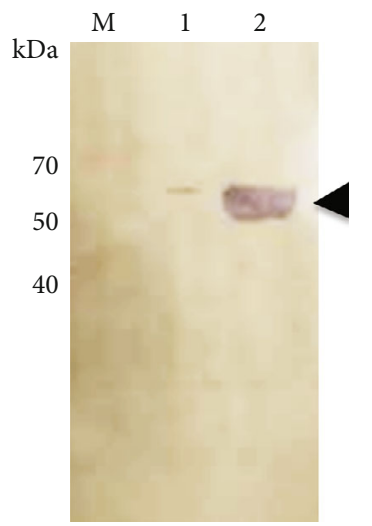

(b)

FIgURe 5: Purification and identification of rNTHiENO. Protein was resolved by SDS-PAGE on 12\% polyacrylamide gel and stained with Coomassie blue. (a) Lane M: molecular weight marker. Lane 1: E. coli Bl21 cell containing the pRSET-A::NTHiENO without IPTG induction. Lane 2: E. coli Bl21 cell containing the pRSET-A::NTHiENO with IPTG induction. Lane 3: insoluble pellet. Lane 4: washing material. Lane 5: the purified rNTHiENO. Identification of rNTHiENO by western blot using a monoclonal antibody anti-His Tag. (b) Lane M: molecular weight marker. Lane 1: pRSET-A::NTHiENO in E. coli BL21, noninduced. Lane 2: purified rNTHiENO. The band corresponding to rNTHiENO $(52.0 \mathrm{kDa})$ is indicated with an arrow.

the NTHi enolase presents five of these motifs; this could indicate that $H$. influenzae use these motifs to have adhesion to exRNA, thus contributing to the colonization and dissemination of bacteria; however, more assays must be done to verify this assumption.

One of the aims of this work was to demonstrate if enolase is expressed on the cell surface of $H$. influenzae. Since enolase is described as a nonclassical export protein due to the lack of signal peptide [44], possible transmembranal helices were located in the enolase sequence by in silico analysis. In these results, a transmembranal (TM) domain is identified in the region comprised by amino acids $\mathrm{Asn}_{105}-\mathrm{Ala}_{124}$ (Supplementary Figure 1). These results allow inferring that the enolase of $H$. influenzae could be anchored in the bacterial membrane through this region. A group of researchers in 2011 identified an alpha helix with hydrophobic characteristics in the enolase of Bacillus subtilis in the position $\mathrm{Ala}_{108}-\mathrm{Leu}_{126}$ and within this region a domain TM ( $\mathrm{Ala}_{110}$ to $\left.\mathrm{Cys}_{118}\right)$ and may be immersed in the membrane of $B$. subtilis [45]. In T. cruzi, a transmembrane domain was also identified in the $\mathrm{N}$-terminal region between the amino acids $\mathrm{Gly}_{105}-\mathrm{Ala}_{122}$ [35]; these latter data agree with those obtained for enolase from $H$. influenzae.

Although the precise mechanism by which enolase is exported to the surface is unknown, one hypothesis is that it was carried out by micromaterials; however, it was observed that transport through vesicles is not significant, so there must be alternative mechanisms to release this protein lacking signal peptide to the medium. On the other hand, it has been observed that this alpha helix is essential for their exporting, since when that region is mutated $\left(\mathrm{Ala}_{108}-\mathrm{Leu}_{126}\right)$ and replaced by another alpha helix (so as not to alter the 


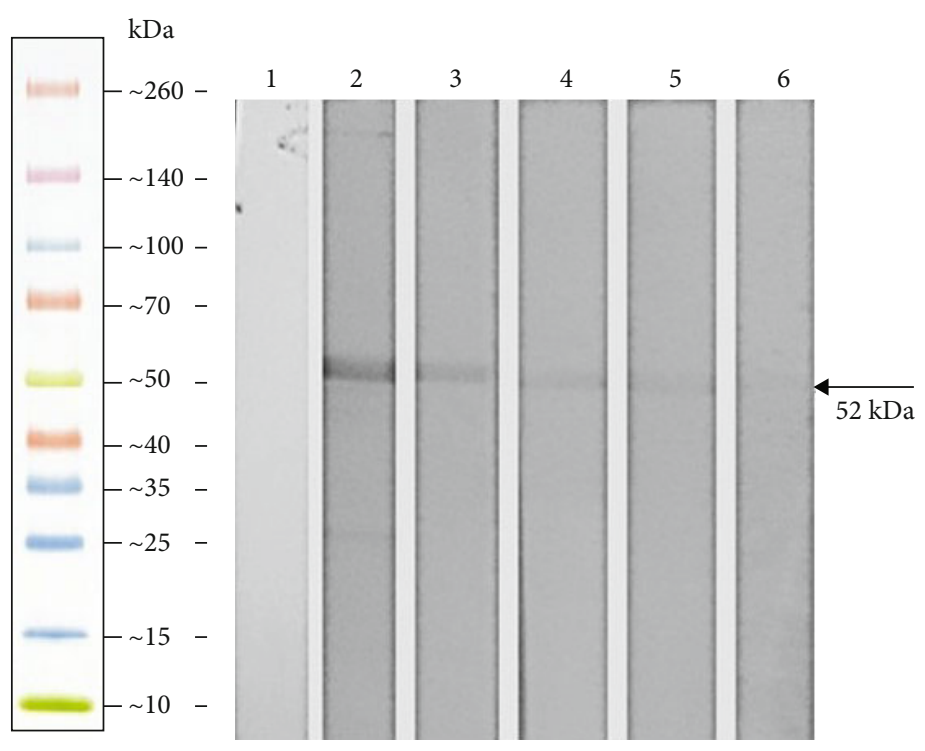

Figure 6: Titer of polyclonal antibodies generated against rNTHiENO. Titration by western blot of the antibodies generated against the recombinant protein. rNTHiENO was migrated on SDS-polyacrylamide gels, and after that, the membranes were electrotransferred to nitrocellulose membranes; as a first antibody, the polyclonal antibody generated at different dilutions was used; as a secondary antibody, a goat anti-rabbit alkaline phosphatase-labeled IgG was used. The image is representative of at least three independent experiments. Lane 1: preimmune serum. Lane 2: dilution 1:1000. Lane 3: dilution 1:10000. Lane 4: dilution 1:20000. Lane 5: dilution 1:30000. Lane 6: dilution $1: 40000$. The weight of the recombinant protein is indicated with an arrow.

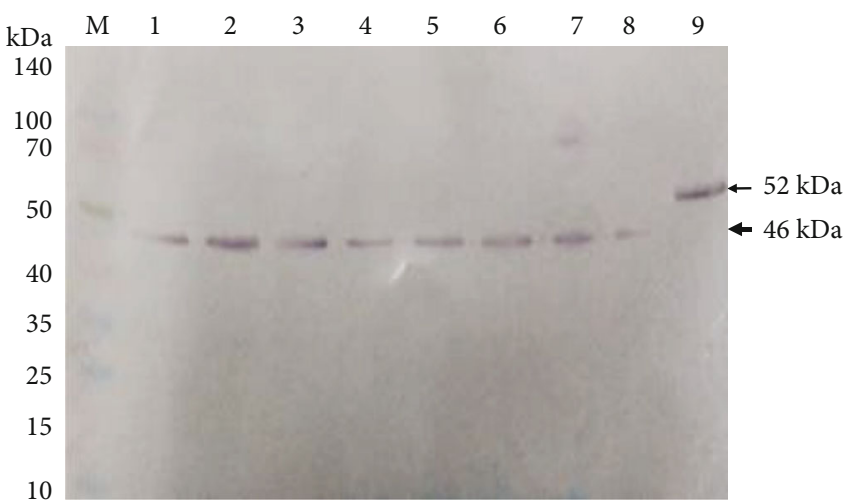

Figure 7: Antibodies anti-rNTHiENO recognize to native enolase of $H$. influenzae typeable and nontypeable. Immunodetection by western blot of the native enolase of $H$. influenzae using antirNTHiENO polyclonal antibodies. Lane M: prestained protein marker. Lanes 1-4: total protein extracts of HibBUAPNAN, HibATCC33, HiNTBUAP96, and HiNTBUAPPAU, respectively. Lanes 5-8: enriched membrane proteins, same order. Lane 9: rNTHiENO purified as positive control. The band corresponding to wild enolase $(46.0 \mathrm{kDa})$ in $H$. influenzae strains is indicated with an arrowhead. The band corresponding to rNTHiENO $(52 \mathrm{kDa})$ is indicated with an arrow.

three-dimensional structure); note that the enolase of $B . s u b$ tilis is no longer secreted into the environment [45].

On the other hand, the immunogenic properties of NTHiENO were analyzed using a bioinformatics approach. When the protein was analyzed with the VaxiJen program, it showed that enolase could function as a protective antigen. In turn, along the enolase sequence, 10 epitopes were pre- dicted for B cells and 13 for CTL cells, and four of them showed overlap. In this regard, previous reports confirm that stimulation with recombinant enolase from Clonorchis sinensis (rCs enolase) leads to the production of IgG1 and IgG2a and that rCs enolase fused with a Bacillus subtilis spore induces Th1/Th2 immune responses [46]. On the other hand, C. albicans enolase can stimulate the secretion of IL-12 and IL-10, in addition to protective antibodies IgG1 and IgG2a isotype [47]. Another study showed that recombinant enolase from $T$. cruzi was recognized by sera from infected patients; this indicates that enolase is recognized by the immune system of the patients and therefore is immunogenic [35]. The use of enolase to trigger a protective immune response was reported in a study carried out by Wang et al. in 2015 , where they observed the participation of enolase in adhesion and invasion processes by Streptococcus iniae in BHK-21 cells (hamster kidney cancer cells); furthermore, immunization with the recombinant protein can confer effective protection against $S$. iniae infection in mice [13]. Another study also reports that $S$. sobrinus rEnolase acts as an immunogenic antigen, observing a correlation between previous immunization of recombinant enolase and decreased oral colonization by S. sobrinus, in the rat model [48].

Further, in Vibrio parahaemolyticus, it was shown that vaccination with recombinant enolase confers effective immunity against a lethal dose of $V$. parahaemolyticus in a mouse model [15]. The protective effect of enolase has also been observed in parasites. For example, a study conducted in India in 2007 showed that Plasmodium falciparum enolase is present on the surface of merozoites, and the use of anti- $P$. falciparum enolase antibodies inhibits its growth in vitro culture; in addition, it was also observed that mice immunized with $\mathrm{r}$-Pfen demonstrated protection against the lethal strain 


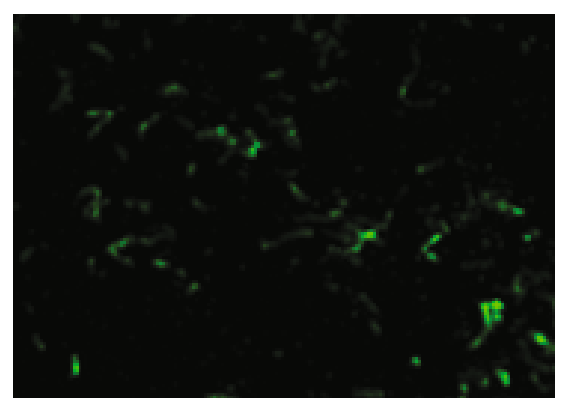

(a)

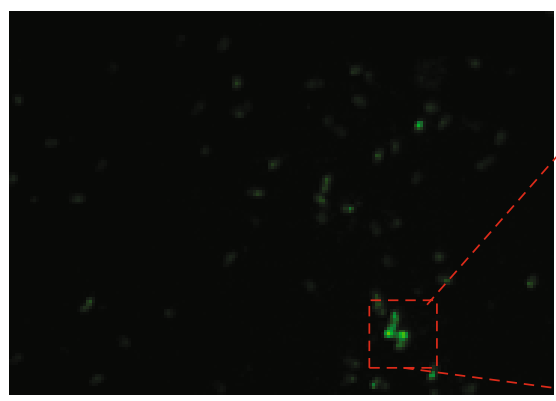

(c)

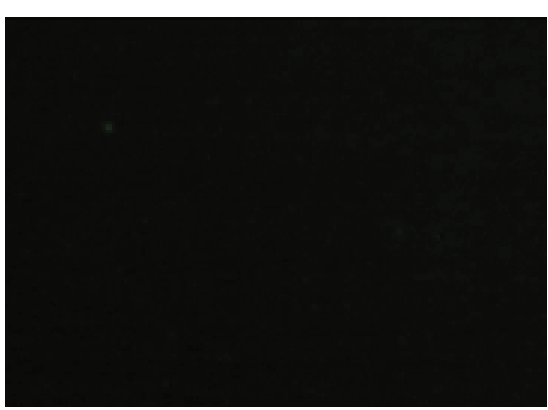

(b)

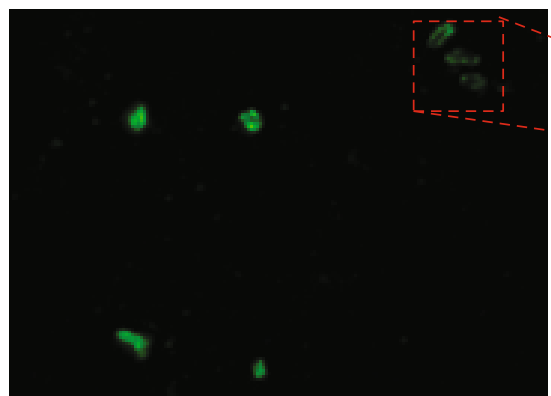

(d)

FIGURE 8: Enolase is exposed in surface in H. influenzae typeable and nontypeable. Immunodetection by immunofluorescence indirect (IFI) in nonpermeabilized $H$. influenzae typeable and nontypeable strains was realized. Anti-rNTHiENO antibodies were used as a first antibody; anti-rabbit FITC-labeled IgG was used as a second antibody. Each image is a representative of at least three independent experiments and captured by a fluorescence microscope. (a) H. influenzae nontypeable (HiBUAP96) with anti-H. influenzae polyclonal antibodies as a positive control. (b) H. influenzae nontypeable (HiBUAP96) with preimmune sera as a negative control. (c) H. influenzae nontypeable (HiBUAP96) with anti-rNTHiENO polyclonal antibodies; the inset shows a digital amplification (300\%) carried out with the ZEISS ZEN lite 2.1 program in order to appreciate the recognition of anti-NTHiENO antibodies in the HiBUAP96 membrane. (d) H. influenzae type b (HiBUAPNAN) with anti-rNTHiENO polyclonal antibodies; the inset shows a digital amplification (300\%) carried out with the ZEISS ZEN lite 2.1 program in order to appreciate the recognition of anti-NTHiENO antibodies in the HiBUAPNAN membrane.

Plasmodium yoelii 17XL [49]. Similar results were reported for Ascaris suum enolase, where a decrease of 61.13 and $88.62 \%$ is observed in the recovery of larvae and eggs, from mice previously immunized with recombinant enolase and later experimentally infected with 2500 larvae of A. suum; suggesting once again, enolase is a vaccine candidate against A. suum [50]. On the other hand, it has been reported that enolase is involved in cancer, systemic fungal disease, and dental diseases [11], and it has even been reported that the expression of enolase on the surface of lung cancer cells promotes its migration or metastasis [51, 52]. Given its importance in different pathological events, enolase has been described as an immunodominant antigen, considered as a potential vaccine candidate $[34,50]$ in fungi, bacteria, and parasites, and as therapeutic targets against cancer.

The above studies allow us to propose $H$. influenzae enolase as a possible immunogen to be studied in the development of a vaccine, also taking into account the in silico analysis which evidences the immunogenic characteristics of this protein.

Finally, immunofluorescence assays showed that enolase is present on the cell surface in both nontypeable (noncapsulated) and typeable (capsulated) $H$. influenzae strains, although the recognition pattern was different, homogeneous in the nontypeable and in the form of spots in the typeable, probably due to the presence of the capsule that interferes with an adequate anchorage by the enolase. However, these results demonstrate in an important way the presence of the enolase on the bacterial surface, and in addition, the antibodies generated specifically recognize this protein.

These results are in agreement with those described in other bacterial models, where the presence of enolase on the bacterial surface has been described such as Streptococcus pneumoniae, Streptococcus pyogenes, Staphylococcus aureus, Mycoplasma fermentans, Pseudomonas aeruginosa, and Mycobacterium tuberculosis [29, 31, 53-55]. Our results indicate that the surface enolase of a bacterium could be a key molecule in pathogenesis by facilitating bacterial interaction with host cells, causing invasion of host tissue.

\section{Conclusion}

The present study demonstrates that specific polyclonal antirNTHiENO antibodies can recognize both typeable and nontypeable strains of $H$. influenzae. Furthermore, the results obtained in this work suggest that immunization with rNTHiENO will be able to generate a good immunogenic response and could provide protection against experimental infection caused by capsulated and noncapsulated strains of $H$. influenzae. In addition, we have demonstrated for the first time, to our knowledge, that the $H$. influenzae enolase protein is located on the cell surface. The immunogenic 
properties evidenced by in silico analysis and the surface localization of enolase are important features to consider $H$. influenzae enolase as a potential candidate for vaccine development; however, further studies are needed to confirm that enolase of $H$. influenzae could be a good vaccine candidate.

\section{Data Availability}

All data are available from the corresponding author on reasonable request.

\section{Conflicts of Interest}

The authors declared there are no competing financial interests.

\section{Acknowledgments}

This study was supported by a grant of the PRODEP to ACL (PRODEP/511-6/17-8017) from the Programa de Incorporación de Nuevos Profesores de Tiempo Completo and by a grant of the BUAP-VIEP (54/NAT/06G) to RCRG from the Programa Institucional de Fomento a la Investigación y a la Consolidación de Cuerpos Academicos. Y. Osorio-Aguilar (fellowship number 675962) was a recipient of MSc fellowship from CONACYT-México and currently is a recipient of a Ph.D. fellowship also from CONACYT-México.

\section{Supplementary Materials}

Supplementary 1. Figure S1: NTHiENO transmembrane helix prediction. In order to predict the presence of a transmembrane helix in the enolase sequence, three bioinformatics programs were used: PredictProtein, TMpred, and HMMTOP; these showed very similar results, the presence of a transmembrane helix in the HiENO sequence, and the results obtained in the HMMTOP program are presented. This program predicts the presence of the transmembrane helix from position $\mathrm{Asn}_{105}$ to $\mathrm{Ala}_{124}$ (highlighted in red); it also shows an intracellular or cytoplasmic region $\mathrm{Met}_{1}-\mathrm{Ser}_{104}$ and the extracellular region Ser $_{125}-\mathrm{Tyr}_{437}$. (Supplementary Materials)

\section{References}

[1] T. F. Murphy, H. Faden, L. O. Bakaletz et al., "Nontypeable Haemophilus influenzae as a pathogen in children," The Pediatric Infectious Disease Journal, vol. 28, no. 1, pp. 43-48, 2009.

[2] K. P. Lemon, V. Klepac-Ceraj, H. K. Schiffer, E. L. Brodie, S. V. Lynch, and R. Kolter, "Comparative analyses of the bacterial microbiota of the human nostril and oropharynx," mBio, vol. 1, no. 3, 2010.

[3] D. C. Turk, "The pathogenicity of Haemophilus influenzae," Journal of Medical Microbiology, vol. 18, no. 1, pp. 1-16, 1984.

[4] M. Pittman, "Variation and type specificity in the bacterial species Hemophilus influenzae," The Journal of Experimental Medicine, vol. 53, no. 4, pp. 471-492, 1931.

[5] C. F. Clementi and T. F. Murphy, "Non-typeable Haemophilus influenzae invasion and persistence in the human respiratory tract," Frontiers in Cellular and Infection Microbiology, vol. 1, p. 1, 2011.
[6] A. Agrawal and T. F. Murphy, "Haemophilus influenzae infections in the $H$. influenzae type b conjugate vaccine era," Journal of Clinical Microbiology, vol. 49, no. 11, pp. 37283732, 2011.

[7] J. van Eldere, M. P. Slack, S. Ladhani, and A. W. Cripps, "Nontypeable Haemophilus influenzae, an under-recognised pathogen," The Lancet Infectious Diseases, vol. 14, no. 12, pp. 1281-1292, 2014.

[8] J. D. Langereis and M. I. de Jonge, "Invasive disease caused by nontypeable Haemophilus influenzae," Emerging Infectious Diseases, vol. 21, no. 10, pp. 1711-1718, 2015.

[9] M. Giufrè, L. Daprai, R. Cardines et al., "Carriage of Haemophilus influenzae in the oropharynx of young children and molecular epidemiology of the isolates after fifteen years of H. influenzae type b vaccination in Italy," Vaccine, vol. 33, no. 46, pp. 6227-6234, 2015.

[10] H. Ji, J. Wang, J. Guo et al., "Progress in the biological function of alpha-enolase," Animal Nutrition, vol. 2, no. 1, pp. 12-17, 2016.

[11] V. Pancholi, "Multifunctional alpha-enolase: its role in diseases," Cellular and Molecular Life Sciences, vol. 58, no. 7, pp. 902-920, 2001.

[12] V. Pancholi and G. S. Chhatwal, "Housekeeping enzymes as virulence factors for pathogens," International Journal of Medical Microbiology, vol. 293, no. 6, pp. 391-401, 2003.

[13] J. Wang, K. Wang, D. Chen et al., "Cloning and characterization of surface-localized $\alpha$-enolase of Streptococcus iniae, an effective protective antigen in mice," International Journal of Molecular Sciences, vol. 16, no. 12, pp. 14490-14510, 2015.

[14] E. Glowalla, B. Tosetti, M. Kronke, and O. Krut, "Proteomicsbased identification of anchorless cell wall proteins as vaccine candidates against Staphylococcus aureus," Infection and Immunity, vol. 77, no. 7, pp. 2719-2729, 2009.

[15] W. Jiang, X. Han, Q. Wang et al., "Vibrio parahaemolyticus enolase is an adhesion-related factor that binds plasminogen and functions as a protective antigen," Applied Microbiology and Biotechnology, vol. 98, no. 11, pp. 4937-4948, 2014.

[16] A. Carabarin-Lima, P. Lozano-Zarain, M. Castañeda-Lucio et al., "Flagellar expression in clinical isolates of non-typeable Haemophilus influenzae," Journal of Medical Microbiology, vol. 66, no. 5, pp. 592-600, 2017.

[17] S. Kumar, G. Stecher, M. Li, C. Knyaz, and K. Tamura, "MEGA $\mathrm{X}$ : molecular evolutionary genetics analysis across computing platforms," Molecular Biology and Evolution, vol. 35, no. 6, pp. 1547-1549, 2018.

[18] D. Zakrzewicz, S. Bergmann, M. Didiasova et al., "Hostderived extracellular RNA promotes adhesion of Streptococcus pneumoniae to endothelial and epithelial cells," Scientific Reports, vol. 6, no. 1, p. 37758, 2016.

[19] F. Jalalvand and K. Riesbeck, "Haemophilus influenzae: recent advances in the understanding of molecular pathogenesis and polymicrobial infections," Current Opinion in Infectious Diseases, vol. 27, no. 3, pp. 268-274, 2014.

[20] J. Campos, M. Hernando, F. Román et al., “Analysis of invasive Haemophilus influenzae infections after extensive vaccination against H. influenzae type b," Journal of Clinical Microbiology, vol. 42, no. 2, pp. 524-529, 2004.

[21] A. E. de Almeida, I. de Filippis, A. O. Abreu, D. G. Ferreira, A. L. Gemal, and K. B. Marzochi, "Occurrence of Haemophilus influenzae strains in three Brazilian states since the introduction of a conjugate Haemophilus influenzae type b vaccine," 
Brazilian Journal of Medical and Biological Research, vol. 38, no. 5, pp. 777-781, 2005.

[22] R. C. Zanella, M. C. Brandileone, A. L. Andrade et al., "Evaluation of Haemophilus influenzae type b carrier status among children 10 years after the introduction of Hib vaccine in Brazil," Memórias do Instituto Oswaldo Cruz, vol. 110, no. 6, pp. 755-759, 2015.

[23] M. K. Rodríguez, C. I. Agudelo, and C. Duarte, "Invasive Haemophilus influenzae isolates in children younger than 5 years: distribution of serotypes and antimicrobial sensitivity, SIREVA II, Colombia 2002-2013," Infection, vol. 19, no. 2, pp. 67-74, 2015.

[24] Z. Roaa, A. Abdulsalam, G. Shahid, B. Kamaldeen, and A. F. Tariq, "Pediatric invasive disease due to Haemophilus influenzae serogroup A in Riyadh, Saudi Arabia: case series," Journal of Infection in Developing Countries, vol. 10, no. 5, pp. 528532, 2016.

[25] R. Rappuoli, "Reverse vaccinology," Current Opinion in Microbiology, vol. 3, no. 5, pp. 445-450, 2000.

[26] R. Rappuoli, "Reverse vaccinology, a genome-based approach to vaccine development," Vaccine, vol. 19, no. 17-19, pp. 2688-2691, 2001.

[27] M. Meunier, M. Guyard-Nicodeme, E. Hirchaud, A. Parra, M. Chemaly, and D. Dory, "Identification of novel vaccine candidates against Campylobacter through reverse vaccinology," Journal of Immunology Research, vol. 2016, Article ID 5715790, 9 pages, 2016.

[28] X. Liu, C. Zheng, X. Gao, J. Chen, and K. Zheng, "Complete molecular and immunoprotective characterization of Babesia microti enolase," Frontiers in Microbiology, vol. 8, p. 622, 2017.

[29] S. Bergmann, M. Rohde, G. S. Chhatwal, and S. Hammerschmidt, "alpha-Enolase of Streptococcus pneumoniae is a plasmin(ogen)-binding protein displayed on the bacterial cell surface," Molecular Microbiology, vol. 40, no. 6, pp. 1273-1287, 2001.

[30] S. Bergmann, D. Wild, O. Diekmann et al., "Identification of a novel plasmin(ogen)-binding motif in surface displayed alphaenolase of Streptococcus pneumoniae," Molecular Microbiology, vol. 49, no. 2, pp. 411-423, 2003.

[31] I. Ceremuga, E. Seweryn, I. Bednarz-Misa et al., "Enolase-like protein present on the outer membrane of Pseudomonas aeruginosa binds plasminogen," Folia Microbiologia (Praha), vol. 59, no. 5, pp. 391-397, 2014.

[32] E. de la Torre-Escudero, R. Manzano-Roman, R. Perez-Sanchez, M. Siles-Lucas, and A. Oleaga, "Cloning and characterization of a plasminogen-binding surface-associated enolase from Schistosoma bovis," Veterinary Parasitology, vol. 173, no. 1-2, pp. 76-84, 2010.

[33] M. Arce-Fonseca, M. C. Gonzalez-Vazquez, O. RodriguezMorales et al., "Recombinant enolase of Trypanosoma cruzi as a novel vaccine candidate against Chagas disease in a mouse model of acute infection," Journal of Immunology Research, vol. 2018, Article ID 8964085, 14 pages, 2018.

[34] P. Sundstrom and G. R. Aliaga, "Molecular cloning of cDNA and analysis of protein secondary structure of Candida albicans enolase, an abundant, immunodominant glycolytic enzyme," Journal of Bacteriology, vol. 174, no. 21, pp. 67896799, 1992.

[35] A. Carabarin-Lima, O. Rodriguez-Morales, M. C. GonzalezVazquez et al., "In silico approach for the identification of immunological properties of enolase from Trypanosoma cruzi and its possible usefulness as vaccine in Chagas disease," Parasitology Research, vol. 113, no. 3, pp. 1029-1039, 2014.

[36] H. Hara, H. Ohta, T. Inoue et al., "Cell surface-associated enolase in Actinobacillus actinomycetemcomitans," Microbiology and Immunology, vol. 44, no. 5, pp. 349-356, 2000.

[37] A. Derbise, Y. P. Song, S. Parikh, V. A. Fischetti, and V. Pancholi, "Role of the C-terminal lysine residues of streptococcal surface enolase in Glu- and Lys-plasminogen-binding activities of group A streptococci," Infection and Immunity, vol. 72, no. 1, pp. 94-105, 2004.

[38] A. K. Ghosh, I. Coppens, H. Gardsvoll, M. Ploug, and M. Jacobs-Lorena, "Plasmodium ookinetes coopt mammalian plasminogen to invade the mosquito midgut," Proceedings of the National Academy of Sciences of the United States of America, vol. 108, no. 41, pp. 17153-17158, 2011.

[39] K. Lahteenmaki, P. Kuusela, and T. K. Korhonen, "Bacterial plasminogen activators and receptors," FEMS Microbiology Reviews, vol. 25, no. 5, pp. 531-552, 2001.

[40] M. N. Jones and R. G. Holt, "Cloning and characterization of an $\alpha$-enolase of the oral pathogen Streptococcus mutans that binds human plasminogen," Biochemical and Biophysical Research Communications, vol. 364, no. 4, pp. 924-929, 2007.

[41] G. Vanegas, W. Quinones, C. Carrasco-Lopez, J. L. Concepcion, F. Albericio, and L. Avilan, "Enolase as a plasminogen binding protein in Leishmania mexicana," Parasitology Research, vol. 101, no. 6, pp. 1511-1516, 2007.

[42] E. K. Hanson, H. Lubenow, and J. Ballantyne, "Identification of forensically relevant body fluids using a panel of differentially expressed microRNAs," Analytical Biochemistry, vol. 387, no. 2, pp. 303-314, 2009.

[43] M. J. López-López, I. C. Rodríguez-Luna, E. E. Lara-Ramírez, M. López-Hidalgo, C. G. Benítez-Cardoza, and X. Guo, "Biochemical and biophysical characterization of the enolase from Helicobacter pylori," BioMed Research International, vol. 2018, Article ID 9538193, 12 pages, 2018.

[44] V. Kainulainen and T. K. Korhonen, "Dancing to another tune-adhesive moonlighting proteins in bacteria," Biology (Basel), vol. 3, no. 1, pp. 178-204, 2014.

[45] C. K. Yang, H. E. Ewis, X. Zhang et al., "Nonclassical protein secretion by Bacillus subtilis in the stationary phase is not due to cell lysis," Journal of Bacteriology, vol. 193, no. 20, pp. 5607-5615, 2011.

[46] X. Wang, W. Chen, Y. Tian et al., "Surface display of Clonorchis sinensis enolase on Bacillus subtilis spores potentializes an oral vaccine candidate," Vaccine, vol. 32, no. 12, pp. 1338-1345, 2014.

[47] W. Li, X. Hu, X. Zhang et al., "Immunisation with the glycolytic enzyme enolase confers effective protection against Candida albicans infection in mice," Vaccine, vol. 29, no. 33, pp. 5526-5533, 2011.

[48] M. Dinis, D. Tavares, I. Veiga-Malta et al., "Oral therapeutic vaccination with Streptococcus sobrinus recombinant enolase confers protection against dental caries in rats," The Journal of Infectious Diseases, vol. 199, no. 1, pp. 116-123, 2009.

[49] I. Pal-Bhowmick, M. Mehta, I. Coppens, S. Sharma, and G. K. Jarori, "Protective properties and surface localization of Plasmodium falciparum enolase," Infection and Immunity, vol. 75, no. 11, pp. 5500-5508, 2007.

[50] N. Chen, Z. G. Yuan, M. J. Xu et al., "Ascaris suum enolase is a potential vaccine candidate against ascariasis," Vaccine, vol. 30, no. 23, pp. 3478-3482, 2012. 
[51] K. C. Hsiao, N. Y. Shih, H. L. Fang et al., "Surface $\alpha$-enolase promotes extracellular matrix degradation and tumor metastasis and represents a new therapeutic target," PLoS One, vol. 8, no. 7, article e69354, 2013.

[52] M. Capello, S. Ferri-Borgogno, P. Cappello, and F. Novelli, “ $\alpha$ Enolase: a promising therapeutic and diagnostic tumor target," The FEBS Journal, vol. 278, no. 7, pp. 1064-1074, 2011.

[53] A. Yavlovich, H. Rechnitzer, and S. Rottem, "Alpha-enolase resides on the cell surface of Mycoplasma fermentans and binds plasminogen," Infection and Immunity, vol. 75, no. 12, pp. 5716-5719, 2007.

[54] À. Díaz-Ramos, A. Roig-Borrellas, A. García-Melero, and R. López-Alemany, " $\alpha$-Enolase, a multifunctional protein: its role on pathophysiological situations," Journal of Biomedicine \& Biotechnology, vol. 2012, Article ID 156795, 12 pages, 2012.

[55] A. Rahi, S. K. Matta, A. Dhiman et al., "Enolase of Mycobacterium tuberculosis is a surface exposed plasminogen binding protein," Biochimica et Biophysica Acta (BBA)-General Subjects, vol. 1861, no. 1, pp. 3355-3364, 2017.

[56] N. Saitou and M. Nei, "The neighbor-joining method: a new method for reconstructing phylogenetic trees," Molecular Biology and Evolution, vol. 4, no. 4, pp. 406-425, 1987.

[57] J. Felsenstein, "Confidence limits on phylogenies: an approach using the bootstrap," Evolution, vol. 39, no. 4, pp. 783-791, 1985.

[58] E. Zuckerkandl and L. Pauling, "Evolutionary divergence and convergence in proteins," in Evolving genes and proteins, pp. 97-166, Elsevier, 1965. 